\title{
INFLUÊNCIA DO ALÍVIO DE TENSÕES NO PROCESSO DE SOLDAGEM COM REVESTIMENTO DURO DEPOSITADO NO AÇO ASTM A 217 Gr WC9
}

\author{
INFLUENCE OF TENSION RELIEF IN THE HARDFACING WELDING PROCESS \\ PLACED IN ASTM STEEL AT 217 Gr WC9
}

\author{
Solange Pereira dos Santos Farah ${ }^{\mathrm{I}}$ \\ Edmilson Aparecido de Souza ${ }^{\text {II }}$ \\ Alessandro Fraga Farah ${ }^{\text {III }}$ \\ Alessandro Márcio Hakme da Silva ${ }^{\mathrm{IV}}$
}

\begin{abstract}
RESUMO
Com o grande crescimento das indústrias dos diversos segmentos como o sucroalcooleiro, papel e celulose, alimentos, bebidas e outros, as empresas vêm investindo e buscando cada vez mais novas tecnologias para se tornarem cada vez mais competitivas no mercado. O processo de fundição, que proporcionou a evolução e desenvolvimento da metalurgia desde há muito tempo, ainda continua sendo o principal processo utilizado na fabricação de peças devido à sua grande versatilidade em obtenção de materiais com boas propriedades mecânicas e, também, pela possibilidade de adicionar elementos de liga nestes materiais fundidos. Entretanto, para um melhor desempenho em serviço, algumas peças devem ser revestidas. Este trabalho tem por objetivo estudar o comportamento do aço fundido ASTM A217- Gr WC9 quando submetido ao processo de soldagem com revestimento duro, com e sem o tratamento de alívio de tensões. O processo de soldagem com revestimento duro, também chamado de Hardfacing, atualmente não se aplica em recuperações localizadas por se desconhecer os efeitos causados por falta do alívio de tensões. Sendo assim, hoje se tem que retirar toda a solda já depositada, quando há ocorrência de trincas, poros ou inclusões não metálicas, que atrapalha a qualidade exigida em projeto. Aplica-se solda de metal base novamente, e então é realizada a usinagem do chanfro para a nova soldagem por revestimento duro. Para as avaliações das propriedades foram confeccionadas amostras nas mesmas condições do processo na indústria, de onde foram retirados corpos de prova para os ensaios de microdureza, macrografia e líquido penetrante. Os resultados obtidos não apresentaram resultados significativos que justifiquem a aplicação do tratamento de alívio de tensões nos revestimentos duros.
\end{abstract}

Palavras-chave: Aço fundido ASTM A217-Gr WC9. Revestimento duro. Alívio de tensões.

\begin{abstract}
With the great growth of industries in various segments such as sugar and alcohol, paper and cellulose, food, beverages and others, companies have been investing and seeking more and

${ }^{\text {I }}$ Profa. Mestre da Faculdade de Tecnologia Deputado Waldyr Alceu Trigo de Sertãozinho (Fatec-Stz) - São Paulo - Brasil. E-mail: solangepfarah@gmail.com

II Tecnólogo em Mecânica: Processos de Soldagem da Faculdade de Tecnologia Deputado Waldyr Alceu Trigo de Sertãozinho (Fatec-Stz) - São Paulo - Brasil. E-mail: edmilson.asouza80@gmail.com

III Prof. Dr. da Faculdade de Tecnologia Deputado Waldyr Alceu Trigo de Sertãozinho (Fatec-Stz) - São Paulo Brasil. E-mail: alessandro.farah@fatec.sp.gov.br

IV Prof. Dr. da Faculdade de Tecnologia Deputado Waldyr Alceu Trigo de Sertãozinho (Fatec-Stz) - São Paulo Brasil. E-mail: alessandro.silva72@fatec.sp.gov.br
\end{abstract}




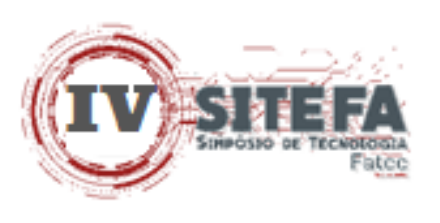

more new technologies to become more and more competitive in the market. The casting process, which provided the evolution and development of metallurgy for a long time, is still the main process used in the manufacture of parts due to its great versatility in obtaining materials with good mechanical properties and also the possibility of adding elements of alloy in these cast materials. However, for best performance in service, some parts must be coated. This work aims to study the behavior of cast steel ASTM A217-Gr WC9 when submitted to the hard coating welding process, with and without stress relief treatment. The hard-coated welding process, also called Hardfacing, is currently not applied to localized restorations because the effects caused by the lack of stress relief are not known. Therefore, today you have to remove all the solder already deposited, when there are cracks, pores, or non-metallic inclusions, which impairs the quality required in the project. The base metal weld is applied again, and then the chamfer is machined for the new hard coat weld. For the evaluation of the properties, samples were made under the same conditions as the process in the industry, from which specimens were taken for microhardness, macrography and penetrating liquid tests. The results obtained did not show significant results that justify the application of stress relief treatment in hard coatings.

Keywords: ASTM A217-Gr WC9 cast steel. Hardfacing. Tension relief.

Data de submissão do artigo: 23/06/2021.

Data de aprovação do artigo: 15/09/2021.

DOI: $10.33635 /$ sitefa.v4i1.171

\section{INTRODUÇÃO}

No contexto atual cada vez mais vem-se buscando materiais mais resistentes com baixo custo de retrabalho e isso não é diferente nos periféricos de uma turbina a vapor. Para melhorar as características dos materiais, eles são submetidos a tratamentos térmicos, revestimentos duros etc., onde podemos melhorar as propriedades e aumentar a vida em serviço dos componentes e peças.

Este trabalho teve por objetivo estudar o comportamento do aço fundido ASTM A217Gr WC9 quando submetido ao processo de soldagem hardfacing com e sem o tratamento de alívio de tensões de periféricos utilizados em turbina a vapor para vedação do vapor vivo, comumente conhecido, como carcaça de fecho rápido. Para essas avaliações serão realizados ensaio de microdureza, macrografia e líquido penetrante, para avaliação das mudanças de suas propriedades nas duas situações.

Foram avaliados corpos de prova do aço fundido ASTM A217-Gr WC9, submetido ao processo de soldagem hardfacing e posteriormente realizado um alívio de tensões, comparandose as propriedades com o corpo de prova que não foi aplicado tratamento térmico.

\section{REVISÃO BIBLIOGRÁFICA}

A concorrência no mercado globalizado e a velocidade do desenvolvimento de novos materiais que possuam propriedades latentes e exclusivas, exigem o aperfeiçoamento das técnicas de fabricação e melhorias constantes, para uma clientela cada vez mais exigente. Ao lado de outros materiais, o aço ainda vem sobrevivendo como um dos materiais mais utilizados devido as suas excelentes propriedades e, também, por novas técnicas e processamentos que aumentam a sua vida em serviço (CHIAVERINI, 2008). 


\subsection{Aços}

O aço é uma liga de natureza moderadamente complexa, visto que, à rigor, os aços comerciais não são ligas binárias, pois apesar de seus principais elementos de liga serem o ferro e o carbono, eles contêm sempre outros elementos secundários, presentes devido aos processos de fabricação. "Aço é a liga de ferro - carbono contendo desde 0,008\% até aproximadamente $2,11 \%$ de carbono, além de certos elementos residuais, resultantes dos processos de fabricação" (CHIAVERINI, 2008).

Portanto, a versatilidade dos aços faz com que eles constituam o mais importante grupo de materiais utilizados na engenharia e na indústria (VAN VLACK, 2008).

\subsection{Aços Resistentes ao Calor}

Os aços resistentes ao calor, também chamados de aços refratários, são aqueles que quando expostos, de modo contínuo ou intermitente, em vários meios de naturezas líquidos ou gasosos sob a ação de temperaturas elevadas, apresentam capacidade de suportar aquelas condições de serviços, apresentando resistência química e mecânica (CHIAVERINI, 2008). De acordo com o autor os principais campos de aplicação desses materiais situam-se nas indústrias do refino do petróleo e química, sendo utilizados em equipamentos para aquecimento (fornos, estufas etc.), em turbinas a gás e à vapor, na indústria automobilística, aeronáutica etc.

Em temperaturas superiores a $400^{\circ} \mathrm{C}$ por exemplo, as propriedades normais que os metais apresentam começam a perder seu significado. Não só as condições de corrosão e oxidação são agravadas como também se verifica apreciável queda na rigidez do material traduzida por aumento deformação plástica sob a ação de esforços mecânicos (CHIAVERINI, 2008).

A resistência mecânica, juntamente com a resistência à corrosão e à oxidação a altas temperaturas, são requisitos exigidos dos aços refratários. Outras características que adquirem importância maior para esses tipos de materiais são a expansão térmica, a estabilidade estrutural e a resistência à fadiga (CHIAVERINI, 2008).

\subsection{Aços fundidos}

Segundo Chiaverini (2008), aço fundido é aquele que é vazado em moldes de areia ou metálicos, onde solidifica e adquire a forma exata da cavidade do molde, de modo a apresentar a forma praticamente definitiva, sem necessidade de qualquer transformação mecânica posterior.

O grande emprego do aço fundido deve-se ao fato de se produzir, por fundição, peças de grande variedade de formas e dimensões, com razoáveis resistência e tenacidade à um custo relativamente baixo. Na prática, sob o ponto de vista de propriedades mecânicas, admite-se geralmente que o aço fundido seja de qualidade inferior ao aço trabalhado. Além disso, é frequente as peças fundidas apresentarem alguns defeitos superficiais ou internos, típicos do processo de fundição (CHIAVERINI, 2008).

\subsection{Aço ASTM A217-Gr WC9}

A liga do aço ASTM A217-Gr WC9 é um material ao cromo-molibdênio para fundição em areia, mundialmente aplicado na indústria de produtores de energia. Este aço é indicado para aplicações nas áreas de Petróleo e Gás, Usinas Térmicas e Nucleares, Indústrias Químicas, 
Fábricas de Fertilizantes, Construção Naval, dessalinização, Tratamento de água, Indústrias de energia, de acordo de acordo com Metal Pipe (2020).

A Tabela 1 informa os valores da composição química do aço ASTM A217-Gr WC9 que foi utilizado para os estudos sobre a influência do Alívio de Tensões.

Tabela 1 - Composição Química nominal do aço ASTM A217 - Gr WC9

\begin{tabular}{c|c|c|c|c|c|c|c}
\hline \multicolumn{7}{c}{ Composição Química (\%) } \\
\hline $\mathbf{C}$ & $\mathbf{S i}$ & $\mathbf{M n}$ & $\mathbf{P}$ & $\mathbf{S}$ & $\mathbf{C r}$ & $\mathbf{M o}$ & $\mathbf{F e}$ \\
\hline $0,05-0,18$ & 0,60 & $0,04-0,70$ & 0,035 & 0,035 & $2,00-2,75$ & $0,9-1,20$ & Bal. \\
\hline
\end{tabular}

Fonte: Norma ASTM A 217-Gr WC9 (2010, p. 2)

Algumas das propriedades mecânicas, tais como: resistência à tração, limite de escoamento e resistência ao impacto do aço ASTM A217-Gr WC9 utilizado neste trabalho, estão classificadas de acordo com a Tabela 2.

Tabela 2 - Propriedades Mecânicas do aço ASTM A217-Gr WC9

\begin{tabular}{c|c|c|c}
\hline $\begin{array}{c}\text { Limite de Resistência } \\
\text { (MPa) }\end{array}$ & $\begin{array}{c}\text { Limite de Escoamento } \\
\text { (MPa) }\end{array}$ & $\begin{array}{c}\text { Alongamento } \\
\mathbf{( \% )}\end{array}$ & $\begin{array}{c}\text { Redução de área } \\
(\%)\end{array}$ \\
\hline $485-655$ & 275 & 20 & 35 \\
\hline
\end{tabular}

Fonte: VISHNUH et al., 2017

\subsection{Fundamentos da Soldagem}

Existem várias definições de solda, segundo diferentes normas. A solda pode ser definida como uma união de peças metálicas, cujas superfícies se tornaram plásticas ou liquefeitas, por ação de calor ou de pressão, ou mesmo de ambos. Poderá ou não ser empregado metal de adição para se executar efetivamente a união (MARQUES; MODENESI; BRACARENSE, 2009).

A soldagem é o mais importante processo de união de metais utilizado industrialmente. Este método de união, tem importante aplicação desde a indústria microeletrônica até a fabricação de navios e outras estruturas com centenas ou milhares de toneladas de peso. A soldagem é utilizada na fabricação de estruturas simples, como grades e portões, assim como em componentes encontrados em aplicações com elevado grau de responsabilidade, como nas indústrias químicas, petrolífera e nuclear e, também, na criação de peças de artesanato, joias e de outros objetos de arte ((MARQUES; MODENESI; BRACARENSE, 2009; WAINER, et al., 2005).

\subsection{Soldagem Tungsten Inert Gas (TIG)}

Soldagem Tungsten Inert Gas (TIG) ou Gas-Shielded Tungsten Arc Welding (GTAW) é um processo que utiliza um eletrodo sólido de tungstênio não consumível. O eletrodo, o arco e a área em volta da poça de fusão da solda são protegidos por uma atmosfera protetora de gás inerte. Se um metal de enchimento é necessário, ele é adicionado no limite da poça de fusão. A soldagem TIG produz uma solda limpa e de alta qualidade. Como não é gerada escória, a chance de inclusão dela no metal de solda é eliminada, e a solda não necessita de limpeza no final do processo. (ESAB, 2020)

O processo é mostrado esquematicamente na Figura 1. 
Figura 1 - Desenho esquemático de uma soldagem Tungsten Inert Gas (TIG)

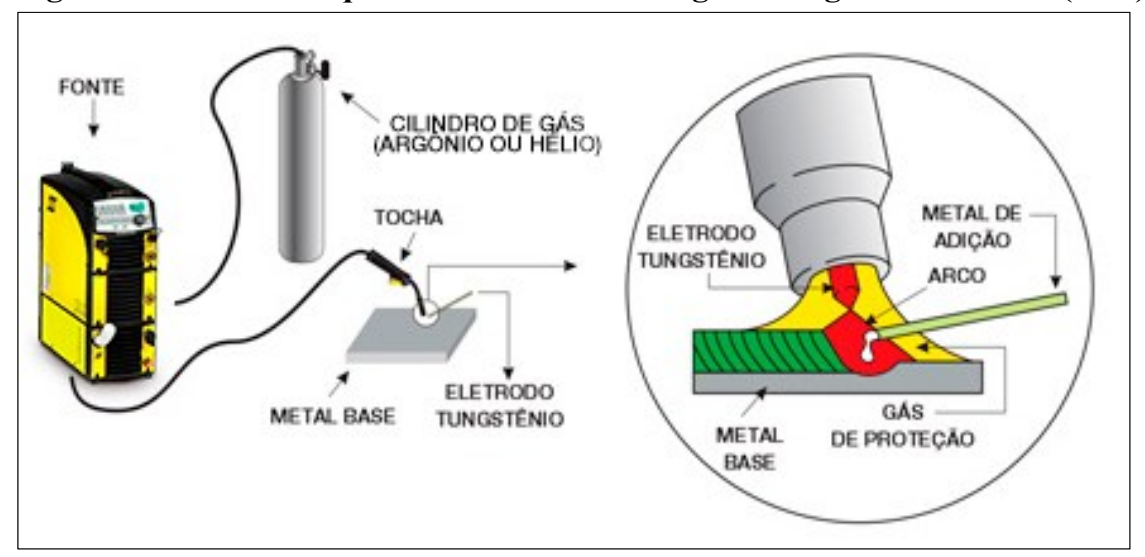

Fonte: ESAB processo soldagem GTAW (2020)

Soldagem TIG pode ser usada para quase todos os metais e o processo pode ser manual ou automático. A soldagem TIG é largamente utilizada para solda com alumínio e com ligas de aço inoxidável onde a integridade da solda é de extrema importância. É também utilizada para juntas de alta qualidade em indústrias nucleares, químicas, aeronáuticas e de alimentos (ESAB, 2020; MARQUES; MODENESI; BRACARENSE, 2009; WAINER, et al., 2005.)

\subsection{Tratamento térmico de alívio de tensão}

Um tratamento térmico é definido como uma combinação de operações de aquecimento e resfriamento aplicado a metais e ligas para obter certas características ou propriedades desejadas. Os tratamentos térmicos têm a finalidade de modificar a microestrutura dos materiais e, consequentemente, suas propriedades mecânicas, as quais estão profundamente relacionadas com a microestrutura (JORGE et al., 2013). Um dos tratamentos utilizados para melhorar a ductilidade de um material é o Alívio de Tensões, que foi utilizado neste trabalho.

Segundo CHIAVERINI (2008), o alívio de tensões consiste no aquecimento do aço a temperaturas abaixo do limite inferior da zona crítica.

Este tratamento térmico tem a finalidade de melhorar as características mecânicas dos materiais através de um aquecimento controlado com temperaturas de subida na ordem de 40 a $150^{\circ} \mathrm{C}$ por hora, normalmente abaixo da temperatura crítica de transformação, para que as propriedades mecânicas como tensão de alongamento e ruptura fiquem estabelecidas entre um limite mínimo aceitável, permanecendo por um período de tempo, normalmente proporcional a espessura das peças, seguido de um resfriamento lento na mesma grandeza da temperatura de subida. Através desse processo, é possível aliviar as tensões resultantes dos processos de fundição, conformação mecânica e soldagem, além de homogeneizar o tamanho dos grãos, regularizarem a textura de fusão e melhorar a usinabilidade. Essas propriedades irão variar de acordo com a temperatura de aquecimento (JORGE et al., 2013; CHAVERINI, 2008).

\section{MATERIAIS E MÉTODOS}

A seguir serão demonstrados os materiais e equipamentos utilizados na elaboração desse trabalho. 


\section{(iv) sinter}

\subsection{Material para soldagem dos corpos de prova}

Para realização deste trabalho utilizaram-se corpos de prova em aço fundido ASTM A217-Gr WC9 que foram retirados de duas placas fundidas nas dimensões de $330 \mathrm{x} 150 \mathrm{x}$ 25mm. A composição química do aço, fornecida pela fundição é mostrada na Tabela 3 abaixo.

Tabela 3 - Placa de aço fundido ASTM A217-Gr WC9

\begin{tabular}{c|c|c|c|c|c|c|c|c|c}
\hline \multicolumn{10}{c}{ Composição Química (\%) } \\
\hline $\mathrm{C}$ & $\mathrm{Si}$ & $\mathrm{Mn}$ & $\mathrm{P}$ & $\mathrm{S}$ & $\mathrm{Cr}$ & $\mathrm{Mo}$ & $\mathrm{Ni}$ & $\mathrm{Cu}$ & $\mathrm{Fe}$ \\
\hline 0,13 & 0,48 & 0,53 & 0,02 & 0,01 & 2,30 & 0,95 & 0,08 & 0,03 & Bal. \\
\hline
\end{tabular}

Fonte: Certificado da Fundição Moreno (2020)

Para soldagem das placas foi utilizado a vareta WI T DUR $06 \varnothing 3,25 \mathrm{~mm}$ que é uma liga de Co-Cr-C-W, de acordo com informações do fabricante WELD-INOX conforme Tabela 4.

Tabela 4 - Composição Química da Vareta WI T DUR 06

\begin{tabular}{c|c|c|c|c|c|c|c|c}
\hline \multicolumn{1}{c}{ Composição Química (\%) } \\
\hline $\mathrm{C}$ & $\mathrm{Si}$ & $\mathrm{Mn}$ & $\mathrm{Cr}$ & $\mathrm{Ni}$ & $\mathrm{Mo}$ & $\mathrm{Fe}$ & $\mathrm{W}$ & Co \\
\hline 1,22 & 1,17 & 0,19 & 29,52 & 2,18 & 0,40 & 2,03 & 4,92 & Bal. \\
\hline
\end{tabular}

Fonte: Certificado da WELD-INOX (2020)

A dureza do Consumível de Solda pode ser vista na Tabela 5 de acordo com informações do fabricante WELD-INOX.

Tabela 5 - Dureza do Consumível WI T DUR 06

\section{Dureza (HRC)}

$$
23-47
$$

Fonte: WELD-INOX (2020)

\subsection{Execução do Processo de Soldagem}

A máquina utilizada foi uma inversora modelo Maxstar 350 com corrente máxima de 350 Amperes do fabricante Miller.

\subsection{Tratamento Térmico de Alívio de Tensões}

Após processo de Soldagem, foi realizado tratamento térmico de Alívio de Tensões em um dos corpos de prova em forno que pode atingir a temperatura máxima de $1000^{\circ} \mathrm{C}$.

\subsection{Ensaio de Microdureza}

Para realização do ensaio de Microdureza foi utilizado o microdurômetro de bancada marca Microtest 3212 B Zwick.

\subsection{Ensaio por Líquido Penetrante}

Para realização do ensaio por líquido penetrante foram utilizados os materiais conforme apresentados na Tabela 6 . 


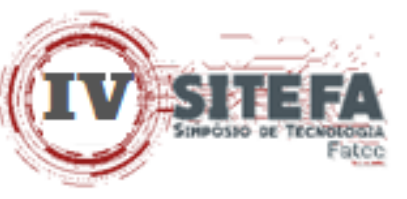

Tabela 6 - Materiais utilizados para o ensaio por Líquido Penetrante

\begin{tabular}{c|c|c|c|c}
\hline & Solvente & Penetrante & Removedor & Revelador \\
\hline Fabricante & METALCHECK & SPOTCHECK & ÁGUA & SPOTCHECK \\
\hline Ref. Coml & TMC $10-5 \mathrm{~L}$ & SKL-WP & N/A & SKD-S2 \\
\hline
\end{tabular}

Fonte: Certificado do fabricante (2019)

\subsection{Preparação dos corpos de Prova}

Os corpos de provas foram usinados na Fresadora universal para uniformizar a espessura deixando-os nas seguintes medidas: comprimento mínimo de $150 \mathrm{~mm}$, largura de $330 \mathrm{~mm}$ e espessura de $20 \mathrm{~mm}$.

\subsection{Seleção dos parâmetros de Soldagem}

Após a preparação, foram selecionados os parâmetros de Soldagem e executados conforme as condições apresentadas na Tabela 7, para cada um dos parâmetros: préaquecimento, consumível de soldagem, interpasse, corrente, tensão, velocidade e tratamento térmico pós-soldagem.

Tabela 7 - Parâmetros de Soldagem

\begin{tabular}{c|c|c|c|c|c}
$\begin{array}{c}\text { Pré- } \\
\text { aquecimento } \\
\left({ }^{\circ} \mathbf{C}\right)\end{array}$ & $\begin{array}{c}\text { Interpass } \\
\mathbf{e} \\
\left({ }^{\circ} \mathbf{C}\right)\end{array}$ & $\begin{array}{c}\text { Tensão } \\
(\mathbf{V})\end{array}$ & $\begin{array}{c}\text { Corrente } \\
(\mathbf{A})\end{array}$ & $\begin{array}{c}\text { Velocidade } \\
(\mathbf{c m} / \mathbf{m i n})\end{array}$ & $\begin{array}{c}\text { Temperatura de } \\
\text { Tratamento Térmico } \\
\text { de Alívio de Tensões } \\
\left({ }^{\circ} \mathbf{C}\right)\end{array}$ \\
\hline $250-400$ & 350 & $10-13$ & $100-120$ & $8-10$ & $680-700$ \\
\hline
\end{tabular}

Fonte: autores desse trabalho (2020)

\subsection{Execução do processo de Soldagem}

A chapa foi soldada na posição plana (1G) utilizando uma máquina de solda Inversora, pelo processo soldagem TIG Tungsten Inert Gas (GTAW), sendo utilizado um maçarico para pré-aquecimento e lápis térmico para controle da temperatura. A Figura 2 mostra a chapa revestida.

Figura 2 - Soldagem dos corpos de prova

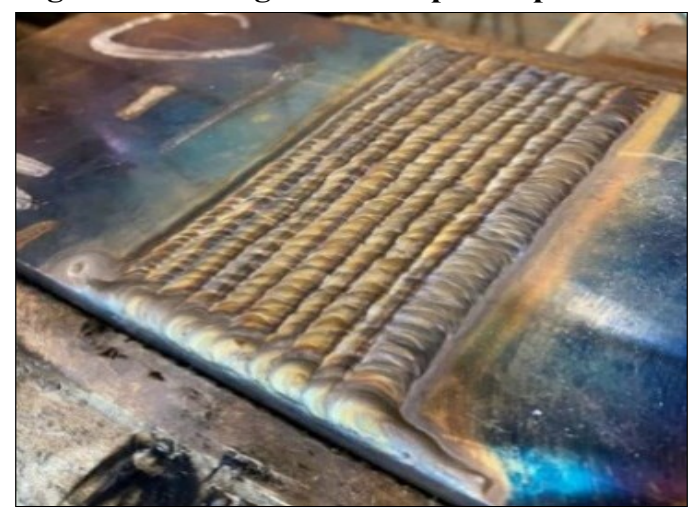

Fonte: fotografada pelos autores (2020) 


\subsection{Tratamento Térmico Pós-Soldagem}

Foi realizado o Tratamento Térmico de Alívio de Tensões na temperatura de $680^{\circ} \mathrm{C}$, permanecendo por duas horas neste patamar. Foi obedecido um ciclo de subida e descida de $80^{\circ} \mathrm{C}$ por hora. O registro da temperatura e do tempo de tratamento foi feito através um gráfico digital, conforme pode ser visto na Figura 3.

Figura 3 - Gráfico de alívio de tensões: curva de temperatura x tempo de subida, patamar e descida

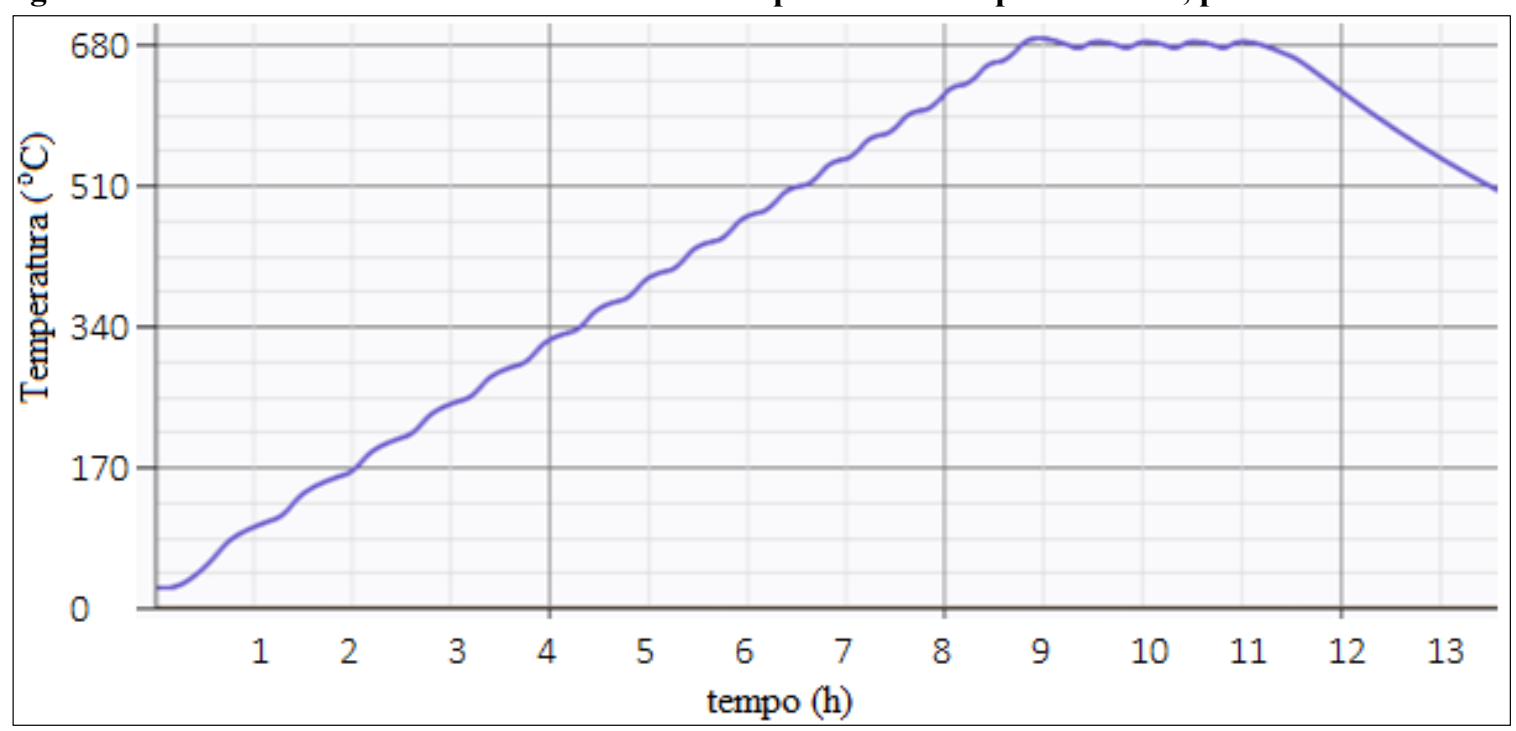

Fonte: emitido pelo forno de alívio de tensões (2020)

\subsection{Preparação do ensaio de microdureza vickers e macrografia}

Foram preparadas duas amostras para execução do ensaio de microdureza pelo processo de Fresamento e posterior sequência de lixamentos com lixas d'água de granulações de 200 até 2000 , polimento para melhor visualização da solda e posterior ataque químico com reagente Nital 3\%. A amostra que identificamos como CP 01 foi submetida ao processo de Tratamento Térmico de Alívio de Tensões, já a amostra denominada CP 02 não foi submetida ao referido processo. As medições foram feitas na face da superfície soldada e preparada para execução do Ensaio de Microdureza Vickers.

Foram retiradas quatro amostras do CP 01 com o Tratamento Térmico de Alívio de Tensões e quatro amostras do CP 02 sem o referido Tratamento, todas para execução do ensaio de macrografia A figura 4 mostra a superfície preparada para execução do Ensaio de Microdureza e Macrografia.

Figura 4 - Amostra para os Ensaios de Microdureza e Macrografia

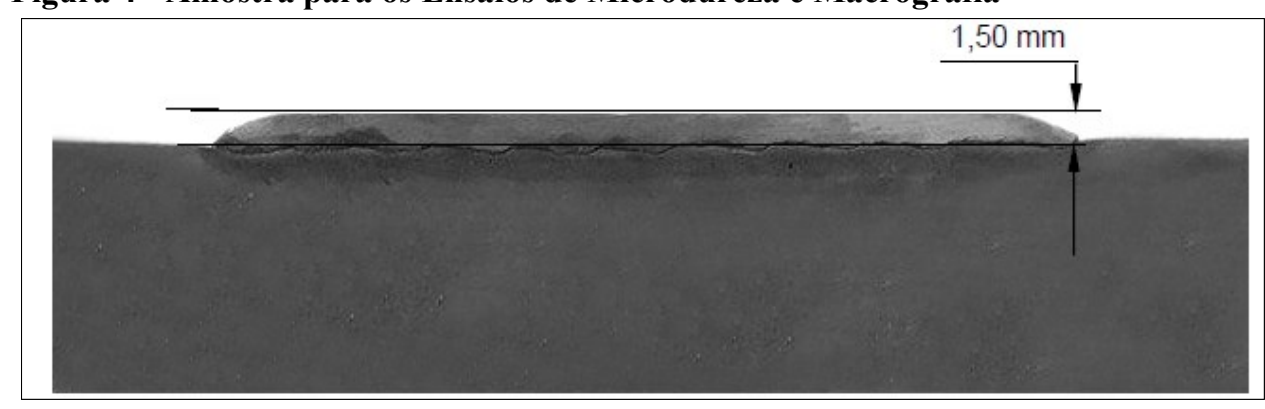

Fonte: autores desse trabalho (2020) 


\subsection{Preparação do corpo de prova para ensaio de líquido penetrante}

Foram preparadas duas amostras para execução do ensaio de Líquido Penetrante pelo processo de escovamento manual e aplica-se, após a limpeza do material, uma camada de líquido penetrante na superfície a ser ensaiada, remove-se o excesso e, com o revelador A amostra que identificamos como CP 01 foi submetida ao processo de Tratamento Térmico de Alívio de Tensões, já a amostra denominada CP 02 não foi submetida ao referido processo. A Figura 5 mostra a superfície preparada e após a execução do Ensaio de Líquido Penetrante.

Figura 5 - Ensaio de Líquido Penetrante
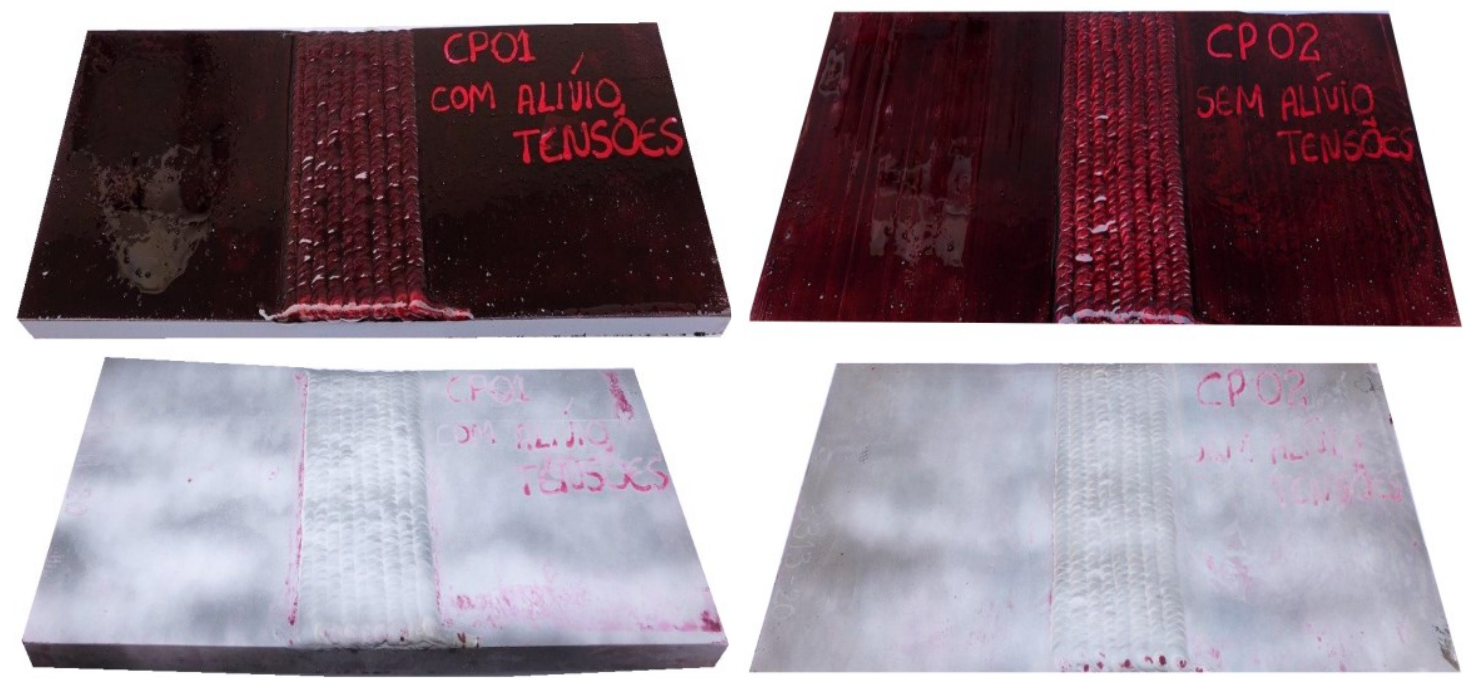

Fonte: autores desse trabalho (2020)

\section{Análises visuais do ensaio de líquido penetrante}

As amostras analisadas após o ensaio de líquido penetrante não apresentaram nenhuma não conformidade. Após a aplicação do revelador, apenas alguns defeitos de superfície tais como porosidades e mordeduras no início da solda, foram evidenciados.

\subsection{Análises comparativas de ensaio de microdureza}

A Tabela 8 compara os valores obtidos para as amostras do CP 02 com três medições nos quais não foram realizados Tratamento Térmico de Alívio de Tensões (T.T.A.T.).

As medições foram realizadas na face superior da solda.

Tabela 8 -Ensaio de Microdureza Vickers para as amostras do CP 02 sem T.T.A.T.

\begin{tabular}{c|c|c|c|c|c}
\hline $\begin{array}{c}\text { Amostras sem Alívio } \\
\text { de Tensões }\end{array}$ & Medida 1 & Medida 2 & Medida 3 & Média (HV) & $\begin{array}{c}\text { Desvio Padrão } \\
\text { (HV) }\end{array}$ \\
\hline $\mathbf{0 1}$ & 468 & 464 & 473 & 468,3 & 3,7 \\
\hline $\mathbf{0 2}$ & 478 & 473 & 473 & 474,7 & 2,4 \\
\hline $\mathbf{0 3}$ & 473 & 468 & 464 & 468,3 & 3,7 \\
\hline $\mathbf{0 4}$ & 468 & 473 & 468 & 469,7 & 2,4 \\
\hline
\end{tabular}

Fonte: autores desse trabalho (2021) 


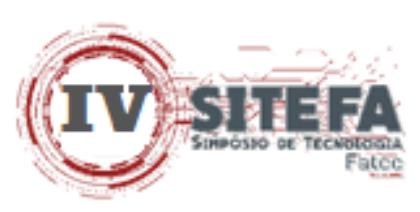

No ensaio de microdureza Vickers as amostras do corpo de prova sem o tratamento de alívio de tensões demonstraram resultados de dureza praticamente uniformes em toda a extensão soldada, com variação média de 468,3 a 474,7HV, e desvios entre 2,4 e 3,7HV.

A Tabela 9 mostra os resultados de microdureza realizados nas amostras do CP $01 \mathrm{com}$ posterior Tratamento Térmico de alívio de tensões. As medições foram realizadas na face superior da solda.

Tabela 9 - Ensaio de Microdureza Vickers para as amostras do CP $01 \mathrm{com}$ T.T.A.T.

\begin{tabular}{c|c|c|c|c|c}
\hline $\begin{array}{c}\text { Amostras com Alívio } \\
\text { de Tensões }\end{array}$ & Medida 1 & Medida 2 & Medida 3 & Média (HV) & $\begin{array}{c}\text { Desvio Padrão } \\
\text { (HV) }\end{array}$ \\
\hline $\mathbf{0 1}$ & 442 & 433 & 437 & 437,3 & 3,7 \\
\hline $\mathbf{0 2}$ & 437 & 433 & 442 & 437,3 & 3,7 \\
\hline $\mathbf{0 3}$ & 446 & 437 & 446 & 443,0 & 4,2 \\
\hline $\mathbf{0 4}$ & 433 & 447 & 442 & 440,7 & 5,8 \\
\hline
\end{tabular}

Fonte: autores desse trabalho (2021)

O corpo de prova submetido ao tratamento térmico de alívio de tensões, apresentou valores de dureza menores que o corpo de prova sem tratamento, e praticamente uniformes em toda a extensão soldada, com variação de 437,3 a 443,0HV, e desvios entre 3,7 e 5,8HV

A análise dos valores obtidos no ensaio de dureza Vickers mostra que o tratamento térmico de alívio de tensões diminuiu a dureza média do revestimento em torno de $7 \%$, não sendo assim tão significativo.

\section{CONCLUSÃO}

Com base nos resultados obtidos, conclui-se que revestimentos utilizados para recuperações localizadas, como o WI T DUR 06, não apresentam reduções significativas de dureza quando o material é submetido ao tratamento térmico de alívio de tensões.

Essa pequena redução de dureza, não justifica o gasto com tratamentos posteriores ao processo de soldagem de recuperação em periféricos de turbinas a vapor.

\section{REFERÊNCIAS}

ASTM A217/A217M - 10 Standard specification for steel castings, martensitic stainless and alloy, for pressure-containing parts, suitable for high-TemperatureService. (American Society for testing and materials) USA, 2010.

CHIAVERINI, Vicente. Aços e ferros fundidos. 7 ed. Associação Brasileira de Metais, 2008.

ESAB. Processo soldagem GTAW. 2020. Disponível em:

https://www.esab.com.br/br/pt/education/blog/processo_soldagem_tig_gtaw.cfm. Acesso em: 07 nov. 2020

JORGE, Jorge Carlos Ferreira; FARAGASSO, Sérgio Maciel; SOUZA, Luís Felipe Guimarães de; BOTT, Ivaní de Souza. Efeito do tratamento térmico pós-soldagem nas propriedades mecânicas e microestruturais de metal de solda de aço de extra alta resistência para utilização em equipamentos de ancoragem. Soldag. Insp. São Paulo, Vol. 18, n. 02, p.137-148, abr/jun. 2013. 
MARQUES, Paulo Villani; MODENESI, Paulo Jose; BRACARENSE, Alexandre Queiroz. Soldagem-Fundamentos e Tecnologia. 3. ed. Belo Horizonte: UFMG, 2009.

METAL PIPE. Aço ASTM A217-Gr WC9. Disponível em: http://metalpipe.com.br/acosligados-low-alloys/index.html. Acesso em 05 dezembro 2020

VAN VLACK, L. H. Princípios de Ciência e Tecnologia dos Materiais. 4. Ed. Rio de Janeiro: Elsevier, 2008.

VISHNUH, V., SUDHAKAR, S., TAMILARASU, K., PRABHAKARAN, P., RAJASEKAR, R. Experimental Analysis of Nitrogen as an Alloying Element in WC9 Grade Steel. Archives of Metallurgy and Materials. 62, 3, 1889-1894. (2017).

WAINER, Emílio; BRANDI, Sérgio Duarte; MELLO, Fábio Décourt Homem. Soldagem Processos e Metalurgia. 5. Ed, São Paulo: Edgard Blücher Ltda, 2005.

WELD-INOX. Produtos-Informações. Disponível em:

http://www.weldinox.com.br/produto-informacoes?id=336\#produtoInt-sup. Acesso em 22 setembro de 2020. 